Start-up-Days

\title{
Voller Erfolg mit mehr als 230 jungen Zahnärzten
}

„Log in to your future” lautete das Motto der CAMLOG Start-up-Days im April 2016 in Frankfurt am Main. Mehr als 230 junge Zahnärztinnen und Zahnärzte waren in

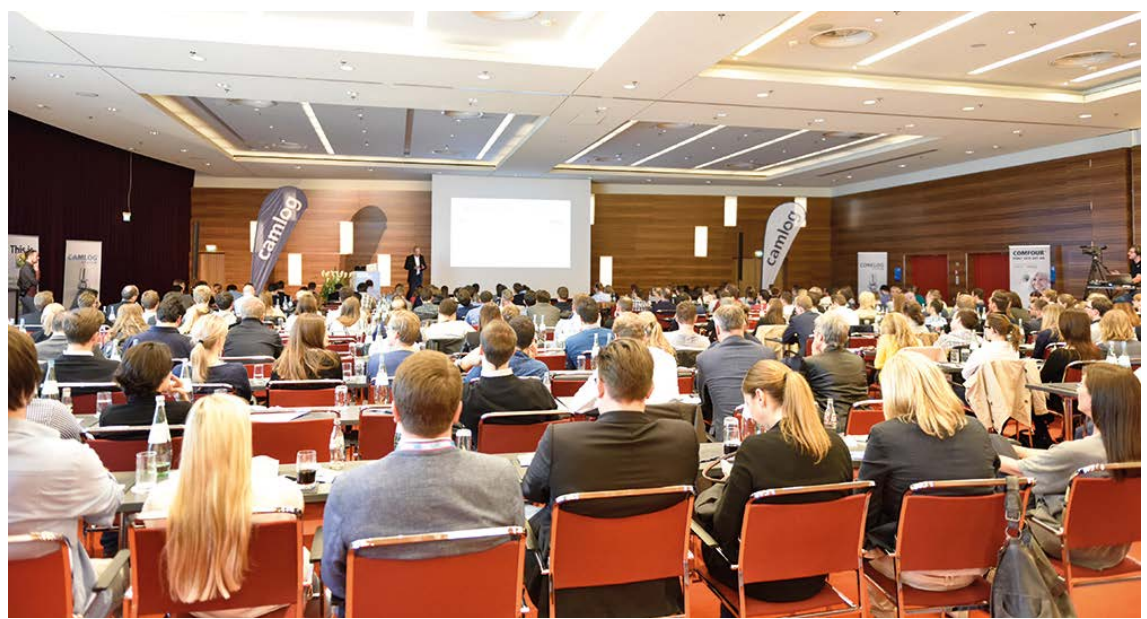

medizinische Berufsausübung inspirieren zu lassen.

„Wir wollen die nächste Generation informieren, inspirieren und motivieren für ihre berufliche Zukunft und Karriere“, stellte Michael Ludwig, Geschäftsführer CAMLOG Vertriebs GmbH, das innovative Fortbildungsformat vor. Dieses war ausgerichtet auf den persönlichen Erfahrungsaustausch mit erfolgreichen Praxisinhabern, die am Freitag über ihre persönlichen Herausforderungen mit der Gründungsphase und Praxisführung berichteten. In Kombination mit den 9 verschiedenen Workshops am Samstag bot die Veranstaltung wertvolles Basiswissen in den Bereichen Betriebswirtschaft, Praxiskonzeption, Mitarbeiterführung, Marketing und der Implantologie. Zudem verloste CAMLOG insgesamt unter den Teilnehmern 8 Hospitationstage. Dass die Veranstaltung ein voller Erfolg war, unterstrich Ludwig bei der Verabschiedung der Teilnehmer mit dem Statement: „Die Veranstaltung wird wiederholt.“

Nach einer Pressemitteilung der CAMLOG Vertriebs GmbH, Wimsheim www.camlog.de 